\title{
As dificuldades de capitalização das pequenas e médias empresas brasileiras
}

\author{
Wagner Cezar Lucato \\ Milton Vieira JÚNior \\ Eng. de Produção da FEAU - UNIMEP
}

Resumo

O propósito central deste artigo é discutir as dificuldades enfrentadas pelas pequenas e médias empresas brasileiras (PMEs) para a aquisição dos bens de capital necessários à atualização de sua base tecnológica. Como parte dessa discussão, foram realizados estudos de caso envolvendo 15 empresas com o objetivo de levantar evidências que possibilitaram estabelecer a seguinte hipótese: as maiores dificuldades enfrentadas pelas PMEs brasileiras para adquirir bens de capital estariam diretamente relacionadas a práticas administrativas incorretas desenvolvidas pelos seus proprietários-gestores e não associadas à indisponibilidade de créditos ou outros fatores relacionados aos mercados onde atuam.

Palavras-chave

Pequenas e médias empresas, bens de capital, práticas gerenciais, lucros.

\section{Capitalization difficulties for the brazilian small and medium size companies}

\begin{abstract}
The purpose of this paper is to discuss the difficulties of the Brazilian small and medium size companies (SMSC) to acquire the capital goods required to update their technological base. A case study comprising 15 SMSC was developed in order to collect evidences that enabled to raise the following hypothesis: the major difficulties faced by the SMSC to acquire capital goods is directly related to a series of mismanagement actions performed by their owner-managers when running their business, and not a result of lack of credit or other market / economic environment driven factor.
\end{abstract}

Key words

Small and medium size companies, capital goods, mismanagement, profits. 


\section{INTRODUĈ̣̃O}

Para desenvolver suas atividades, toda empresa necessita dispor de bens de capital, aqui entendidos como itens tangíveis que compõem o ativo permanente das empresas e destinados à manutenção de suas atividades fins (SILVA et al., 2002). As aquisições desses bens são tratadas no mundo financeiro como dispêndios ou investimentos de capital (LONGENECKER, 1998). Nas empresas, esses investimentos são necessários para a aquisição de novas tecnologias, novos equipamentos e instalações, novos produtos, novos recursos de TI (hardware e software) e, não raro, tudo isso junto.

Este artigo tem como objetivo central examinar as dificuldades encontradas pelas pequenas e médias empresas brasileiras (PMEs) para realizar investimentos em bens de capital. Em especial, se procurará demonstrar que as maiores restrições a essas aquisições encontramse no despreparo dos proprietários-gestores das PMEs e não, como comumente se procura ressaltar, na disponibilidade de crédito para esse segmento de empresas.

Antes porém de iniciar a discussão do tema central deste trabalho, é conveniente estabelecer a dimensão a ser dada ao conceito de pequenas e médias empresas, uma vez que existem várias formas de caracterizá-las. Do ponto de vista qualitativo, as pequenas empresas têm sido definidas como aquelas que podem ser geridas por uma única pessoa, em geral os seus próprios donos (GONÇALVES \& KOPROWSKI, 1995). Na pequena empresa a administração é geralmente feita pelos proprietários ou por seus parentes (ALMEIDA, 1994), os quais freqüentemente trabalham lado a lado com os empregados nas operações diárias da empresa (PICKLE \& ABRAHAMSON, 1990). No entanto, neste artigo será adotada para a caracterização qualitativa das PMEs a definição proposta pelo 2 - Simposio Latino Americano y del Caribe de la Pequeña y Mediana Empresa realizado em Quito, Ecuador, em 1978, segundo a qual são consideradas PMEs aquelas empresas que, não ocupando uma posição de domínio ou monopó-

lio no mercado, são dirigidas por seus próprios donos, que assumem o risco do seu negócio, e não estão vinculadas a outras grandes empresas ou grupos econômicos (PINHEIRO, 1996).

Já sob uma visão quantitativa, a caracterização do porte das PMEs tem recebido no Brasil diversas interpretações. Algumas abordagens, como considera o SEBRAE (SEBRAE, 2004b), diferenciam as micro das pequenas empresas com base no número de empregados. Outras se baseiam no faturamento bruto anual, como é o caso da Secretaria da Receita Federal (BRASIL, 2004), do BNDES (BNDES, 2004c) e do Estatuto da Microempresa (BRASIL, 1999). Para as considerações que serão feitas neste trabalho, será assumido como critério diferenciador do porte das empresas o utilizado pelo Estatuto da Microempresa, que estabelece ser micro a firma cujo faturamento bruto anual é igual ou inferior a $\mathrm{R} \$ 433.755,00$. Acima desse valor e até o limite de R\$ 2.133.222,00 encontram-se as pequenas empresas (BRASIL, 2004). Serão consideradas por este trabalho como médias aquelas firmas que, não sendo nem micro e nem pequenas, tenham um faturamento bruto anual igual ou inferior a $\mathrm{R} \$ 24$ milhões. Dessa forma, assumese no desenvolvimento deste estudo que PMEs são empresas cujo faturamento bruto anual esteja compreendido entre R\$ 434 mil e R \$ 24 milhões.

\section{DIFICULDADES DAS PMEs PARA REALIZAR INVESTIMENTOS EM BENS DE CAPITAL}

\section{Referencial teórico}

Segundo Pickle \& Abrahamson (1990) e Longenecker et al. (1998), os investimentos em bens de capital das PMEs apresentam algumas características que os distinguem dos demais dispêndios realizados por essas empresas. São, em geral, constituídos por valores significativos, necessitam ser realizados antes que os bens adquiridos comecem a produzir os resultados esperados e, muito freqüentemente, não podem ser obtidos com recursos próprios das empresas. Por essas razões, as aquisições de bens de capital deveriam ser realizadas utilizando-se fundos de longo prazo.

\section{- $m$ treze das quinze empresas — pesquisadas a gestão era realizada com base nos saldos bancários, sem levar em conta os demonstrativos contábeis.}

Os mesmos autores mostram ainda que os fundos de longo prazo podem ser obtidos pelas empresas de duas fontes: (a) os capitais próprios, que no âmbito da PMEs limitam-se aos aportes de capital realizados pelos sócios quotistas ou pela retenção e posterior capitalização dos lucros auferidos como resultado das operações da empresa ou (b) os capitais de terceiros, representados por empréstimos de longo prazo tomados junto ao sistema financeiro ${ }^{1}$. 
Associando as características das aquisições dos bens de capital à disponibilidade de recursos para realizá-las, verifica-se que esse tipo de investimento, por sua própria natureza, impõe às empresas severas pressões sobre as suas necessidades de caixa ou, alternativamente, fortes exigências na busca de recursos de terceiros para viabilizá-lo. Como o resultado dessa busca nem sempre se reveste de sucesso, é importante destacar que sem esses capitais as empresas em geral, e as PMEs em particular, podem entrar em um estado de torpor tecnológico que corrói a sua competitividade e os seus lucros. Assim, a análise das dificuldades das PMEs para investir em bens de capital torna-se relevante como forma de contribuição à manutenção ou aumento da competitividade das pequenas e médias empresas brasileiras.

Como conseqüência da estruturação das fontes de capital proposta pela literatura, o presente estudo irá analisar as dificuldades das PMEs para realizar investimentos de capital segundo duas considerações: (a) a das dificuldades associadas aos lucros retidos pelas PMEs e aos aportes de capital feitos pelos seus sócios quotistas (capitais próprios); e (b) a das dificuldades relativas aos empréstimos de longo prazo a serem obtidos junto ao sistema financeiro (capitais de terceiros).

\section{A pesquisa exploratória}

Como parte do presente estudo e para poder avaliar as dificuldades das PMEs na aquisição dos seus bens de capital, foi realizada uma pesquisa qualitativa do tipo exploratório com base no estudo de caso de 15 empresas, cujos faturamentos brutos anuais se situam entre $\mathrm{R} \$ 1,6$ milhão e R\$ 18,2 milhões (BRYMAN, 1995; YIN, 1990).

Essas PMEs, que pertencem a diferentes segmentos de mercado, foram selecionadas com base em três critérios: (a) foram consideradas empresas que necessitavam realizar investimentos de capital para atualizar a sua base tecnológica, (b) trata-se de "amostras com conteúdo" (purposeful sampling), ou seja, casos dos quais se possa extrair grande quantidade de informações relevantes ao tema central deste trabalho (PATTON, 1990) e (c) o critério da acessibilidade às informações relevantes para o estudo pretendido, uma vez que, conforme Bryman (1995) o acesso às organizações pesquisadas e aos dados investigados é um dos problemas mais críticos enfrentados pelos pesquisadores.

Nas empresas selecionadas para a presente investigação adotou-se como método de pesquisa a entrevista não estruturada, realizada junto aos seus proprietáriosgestores e na qual se procurou levantar informações relevantes aos aspectos que serão discutidos ao longo do presente trabalho. Para guiar as entrevistas que foram realizadas, elaborou-se um aide-mémoire para orientar o desenvolvimento dos contatos pessoais, evitando que tópicos importantes para a pesquisa acabassem não sendo perguntados (BRYMAN, 1995). Como informações complementares foram obtidas, como documentação primária, informações financeiras levantadas junto às áreas contábeis das empresas pesquisadas (MARCONI \& LAKATOS, 2003).

Como resultado das entrevistas realizadas, foram identificados 19 pontos relevantes para as discussões do presente trabalho e que podem ser segmentadas em características associadas às empresas pesquisadas e aos seus respectivos gestores. Essas características e os resultados obtidos na pesquisa feita podem ser resumidos na Tabela 1 .

Como se observa, a natureza exploratória dessa pesquisa não possibilita o estabelecimento de conclusões definitivas que pressupõem a utilização de metodologia mais formal de investigação científica. No entanto, segundo Selltiz et al. (1974), o estudo exploratório é recomendado como um passo inicial e como forma de levantamento de hipóteses a serem investigadas por meio de pesquisa futura mais precisa. É exatamente com esses objetivos que os estudos de caso aqui apresentados são considerados.

\section{Dificuldades das PMEs para realizar investimentos em bens de capital sob a perspectiva dos recursos próprios}

\section{Lucros retidos}

Diversos estudos realizados (MOREIRA \& PUGA, 2000; ZONENSCHAIN, 1998; SINGH, 1995) demonstraram que a utilização de recursos próprios é a fonte de capitais mais utilizada pelas empresas brasileiras, não tendo sido identificadas alterações nesse padrão de utilização para os diferentes portes de empresa. Pode-se assim afirmar que tal assertiva é também real para as PMEs no Brasil.

Seria, portanto, de se esperar que, como parte dos recursos próprios, a utilização de lucros retidos fosse uma das parcelas importantes dessa forma de capitalização. Mas, para que isso aconteça, muito obviamente as empresas precisam ter lucro. Em pesquisa realizada pelo SEBRAE-SP junto a 411 micro e pequenas empresas, verificou-se que somente $43 \%$ das empresas pesquisadas apresentavam lucro (SEBRAE, 2004a), o que limitaria no universo das PMEs as possibilidades de utilização dos lucros como forma de capitalização para viabilizar a aquisição dos bens de capital por aquelas empresas.

No entanto, deve-se também considerar que o fato de uma empresa "gerar lucro" não necessariamente significa que ela dispõe de recursos suficientes para satisfazer 
as suas necessidades de investimentos. Em primeiro lugar, porque boa parte desse lucro poderia se destinar ao reforço de capital de giro das PMEs e não necessariamente para permitir novos dispêndios de capital. Em segundo, não se pode também deixar de considerar que do lucro obtido deveria sair, primeiro, o pagamento dos dividendos para remunerar o capital próprio investido na empresa. Somente após, poder-se-ia considerar a utilização da parcela remanescente como fonte de capital para reforçar os dispêndios da empresa. Vê-se portanto que simplesmente obter lucro para a geração de recursos adicionais é uma condição necessária, porém não suficiente. $\mathrm{O}$ montante de lucros obtidos é, em realidade, o que importa.

Mas a situação é ainda mais complicada: sabe-se que a própria determinação do lucro é um problema nas PMEs.
Oliveira (2001) destaca que "os empreendedores não consideram as informações contábeis como auxiliares no seu processo de tomada de decisões, confiando apenas na sua intuição”. Segundo ainda o autor, a contabilidade é vista pelos proprietários-gestores das PMEs como um mal necessário para atender às exigências das autoridades fiscais e tributárias. Em linha com tais afirmações, a pesquisa realizada como parte deste trabalho identificou que em 13 das 15 empresas pesquisadas a gestão era realizada exclusivamente com base no conhecimento dos saldos bancários, sem levar em conta as informações mostradas nos respectivos demonstrativos contábeis e sem conhecer, portanto, o montante de lucro ou de prejuízo gerado pelas operações da empresa. Aliás, 6 das 15 firmas analisadas eram optantes pelo SIMPLES Sistema Integrado de Pagamento de Impostos e Contribui-

Tabela 1: Principais resultados da pesquisa junto a 15 empresas.

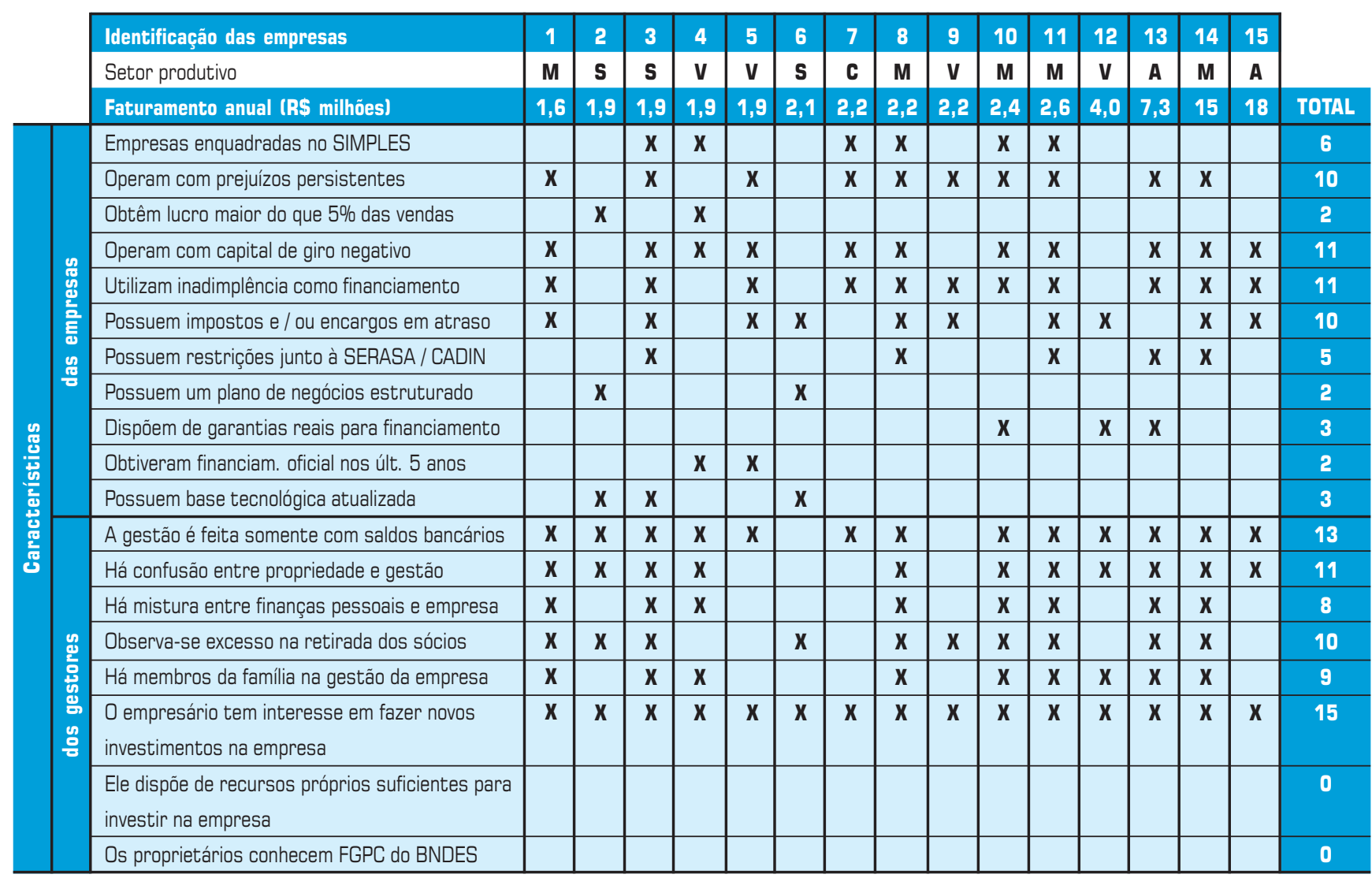

Setores Produtivos

A - Industrial Alimentício (2)

C - Construção Civil (1)

M - Industrial Metalúrgico (5)

S - Serviços (3)

V - Varejo (4) 
ções das Microempresas e Empresas de Pequeno Porte.

Essa alternativa de simplificação fiscal dispensa as empresas de manter uma contabilidade formal, o que permitia àquelas 6 firmas somente escriturar o livro caixa, sem nenhuma possibilidade de conhecer, por meio de seu demonstrativo de resultados, se estavam obtendo lucro. Ainda, outras 7 empresas pesquisadas, ou por utilizar-se de caixa 2 ou por simples negligência de seus proprietários-gestores, também nunca se valiam dos demonstrativos contábeis como forma de conhecer a sua real situação econômica. Como destaca Baty (1994), confiar somente no seu bom senso e no seu tino comercial fará da gestão dos proprietários das PMEs uma tarefa muito arriscada, pois "a contabilidade é uma peça-chave no mundo empresarial”. origens dessa confusão aparentemente vêm de uma simplificação no tratamento dado ao assunto pelos contadores das empresas. Como nas PMEs os sócios são também gestores, esses proprietários-gestores, em geral, estabelecem como seus pró-labores um valor de remuneração mensal que possa atender as suas necessidades cotidianas e que, em 10 das 15 empresas pesquisadas, em nada se relacionava com o valor do trabalho de gestão desenvolvido. Para complicar ainda mais o problema, os valores pagos formalmente a título de pró-labore eram os menores possíveis, sendo o restante da remuneração pago como distribuição de dividendos, visando com isso uma menor carga de impostos e encargos sobre as retiradas feitas. Essa alternativa, embora legal, causa uma enorme confusão entre propriedade e gestão, na medida em que a remuneração do trabalho de gestão acaba sendo feita através do pagamento de pró-labore (devidamente) e também de dividendos (indevidamente). E o que é pior: mesmo na eventualidade de a empresa estar operando com prejuízos, portanto sem dividendos a serem distribuídos, essa prática continua sendo perenizada como se observou em 7 das 10

Como parte do trabalho de investigação realizado, procurou-se também determinar, com base em informações levantadas junto à área contábil, o demonstrativo de resultados real das empresas que não o possuíam, de maneira a se poder conhecer a situação de geração de lucro de todas as 15 empresas pesquisadas. Essa análise, uma vez concluída, mostrou que 10 das 15 empresas vinham apresentando prejuízos persistentes. Das 5 que geravam lucro, apenas 2 o faziam em valores superiores a $5 \%$ das suas vendas líquidas.

Essa investigação dos demonstrativos de resultados das empresas pesquisadas também permitiu identificar outros problemas de gestão que igualmente minavam a sua capacidade de geração de lucros. Em 11 das 15 empresas pesquisadas pode-se identificar uma confusão generalizada entre propriedade e gestão. Explica-se: ser sócio quotista apenas indica que uma pessoa nessa condição possui participação na propriedade de uma empresa. Sua remuneração pelo capital empregado deveria se dar por meio do recebimento de dividendos, pagos com parte do lucro auferido pela empresa em determinado exercício social. Por outro lado, a gestão deveria estar associada ao trabalho desenvolvido para conduzir a empresa aos seus objetivos de maneira eficaz. Por esse trabalho, o sócio, agora na qualidade de gestor, deveria receber a sua remuneração na forma de pró-labore.

Como indicou a pesquisa, na grande maioria das empresas analisadas há uma confusão generalizada entre propriedade e gestão e entre dividendos e pró-labore. As empresas que vinham obtendo prejuízos persistentes.

Esse fato fica ainda agravado pela mistura entre as finanças pessoais dos sócios com as das suas respectivas empresas. Notou-se que em 8 das 15 empresas pesquisadas havia uma nítida mescla entre os compromissos pessoais com os da empresa: contas pessoais eram sistematicamente pagas com recursos da firma e vice-versa. Os valores pessoais quitados pelo caixa da empresa, se adicionados aos pró-labores e dividendos pagos, faziam com que se elevasse, ainda mais, a retirada total dos sócios. Feita essa reconsideração e comparadas com o porte das respectivas empresas, pode-se verificar que em 10 das 15 empresas pesquisadas as retiradas dos sócios foram consideradas excessivas, pois superavam os $10 \%$ do faturamento bruto médio mensal.

Finalizando, é preciso destacar que em 9 das 15 empresas pesquisadas puderam ser encontrados membros "da família" desempenhando funções relevantes na gestão da firma, independentemente de sua real capacitação para realizá-las. Em vários casos ficou patente a falta de preparo e de experiência de colaboradores diretos do proprietário-gestor para a realização eficaz das tarefas do dia-a-dia. Como decorrência, é razoável supor que essa prática também seja um fator que traga um impacto desfavorável sobre o lucro.

Não é de estranhar, portanto, que, frente a tantas práticas gerenciais questionáveis desenvolvidas pelos seus proprietários-gestores, as PMEs tenham dificuldades de obter lucro. Como se observa, as análises realiza- 
das permitem levantar a hipótese de que no universo das PMEs a utilização dos lucros retidos seja uma alternativa muito limitada para a capitalização dessas empresas. Embora a causa dessa escassez de lucros pudesse estar associada à atuação em um segmento industrial de baixa rentabilidade (PORTER, 1986), a inclusão de empresas de múltiplos setores na pesquisa e os dados obtidos e aqui divulgados permitem supor que tal fato esteja muito mais associado ao despreparo dos sócios-gestores das PMEs do que a condições estruturais impostas pelos mercados. De fato, não se pode conceber que um empreendedor administre o seu negócio sem conhecer a informação básica de toda atividade empreendedora: se a sua empresa está gerando lucros. Afinal, como destaca Keynes apud Baty (1994): "O motor que move uma empresa não é a Economia, mas o lucro”. Também não se podem aceitar como boas as práticas de gestão que confundam pró-labores com dividendos, que misturem as finanças pessoais com as da empresa, que admitam pró-labores desvinculados do real valor do trabalho desenvolvido, que aceitem relações familiares que suplantem as qualificações para o trabalho e que propiciem retiradas excessivas em relação à capacidade de geração de caixa das empresas.

Por outro lado, também é preciso ressalvar que os comportamentos dos proprietários-gestores destacados acima podem estar associados a fatores socioculturais profundamente arraigados na cultura empresarial brasileira. Ou possam até estar associados à complicada legislação do país. No entanto, este trabalho não aprofundou a análise dessas questões, motivo pelo qual essa investigação fica como uma sugestão para estudos futuros.

\section{Aportes de capital}

Ainda levando em conta os capitais próprios como fonte de recursos para os investimentos em bens de capital, é possível considerar, além dos lucros retidos, o aporte de capital a ser feito pelos sócios quotistas das PMEs.

É evidente que toda empresa, para existir, pressupõe que seus sócios tenham feito uma cessão inicial de recursos que constituiu o capital inicial dessa empresa e que permitiu a ela fazer as aquisições dos equipamentos e insumos necessários à sua operação. Como já se mencionou neste trabalho, a remuneração desse capital deveria ser realizada com o pagamento regular de dividendos que produzissem uma taxa de retorno igual ao custo de oportunidade que os sócios da empresa teriam se tais recursos tivessem sido aplicados no mercado financeiro, devidamente ajustado pelo grau de risco que essa aplicação na empresa oferece (LONGENECKER et al., 1998).

Porém, se as PMEs, como se verificou, têm dificuldades para gerar lucro, elas ficariam impossibilitadas de remunerar adequadamente o capital nelas investido pelos seus sócios. E, nessas condições, fica também reduzido o interesse do investidor em aportar novos recursos na empresa. Esse é o raciocínio lógico que teoria impõe, mas no mundo real a resposta dos empreendedores mostrou-se diferente.

$\mathrm{Na}$ pesquisa realizada como parte deste trabalho, 15 dos 15 proprietários-gestores entrevistados indicaram que, se tivessem recursos, estariam dispostos a aplicá-los em suas respectivas empresas. É interessante notar que mesmo aqueles 10 cujas empresas estavam operando com prejuízo persistente mostraram essa mesma disposição. Esse comportamento pode sugerir duas leituras distintas: uma positiva - a característica empreendedora dos proprietários das PMEs, que continuariam acreditando incondicionalmente nos negócios que montaram, e outra negativa - eles desconhecem os princípios básicos de como deveria se efetivar a remuneração do capital próprio investido em suas empresas. Este estudo não se aprofundou no esclarecimento dessa questão, razão pela qual esse tema também fica como sugestão para pesquisas futuras.

\section{a pesquisa realizada verificou-se que onze das quinze empresas pesquisadas operavam com capital circulante líquido negativo.}

De qualquer forma, o que se pode observar como parte da investigação feita junto às PMEs pesquisadas foi que nenhum dos seus proprietários-gestores indicou dispor de recursos em volume suficiente para atender aos dispêndios de capital que seriam necessários em suas empresas. Esse fato, aliado aos demais aspectos já relatados, permite sugerir a hipótese de que no universo das PMEs a utilização de aportes de capital realizados pelos seus sócios possa ser também uma alternativa muito limitada para a capitalização dessas empresas.

\section{Dificuldades das PMEs para realizar investimentos em bens de capital sob a perspectiva dos recursos de terceiros}

A outra possível forma de uma PME obter fundos para a realização de investimentos em bens de capital é por meio da obtenção de recursos de terceiros, que no âmbito 
dessas empresas se resumem à utilização de empréstimos levantados junto ao sistema financeiro. Como já se mencionou, em razão de suas características peculiares, esses investimentos deveriam ser realizados com fundos de longo prazo, ou seja, os empréstimos obtidos deveriam permitir uma amortização em um prazo sempre superior a, pelo menos, dois anos.

Embora essa recomendação teórica seja bastante lógica, no mundo real, mais uma vez, as coisas são bem diferentes. Na pesquisa realizada como parte deste trabalho verificou-se que 11 das 15 empresas pesquisadas operavam com capital circulante líquido negativo. Longenecker et al. (1998) mostram que o capital circulante líquido é a diferença entre o ativo circulante e o passivo circulante e que se esse valor é negativo a empresa em questão utiliza fundos de curto prazo para financiar a aquisição de itens de seu ativo permanente, ou seja, bens de capital².
(GONÇALVES, 2000). Porém, é necessário que essa discussão seja colocada sob a perspectiva adequada.

De fato, não se pode afirmar que a disponibilidade de créditos de longo prazo para as PMEs seja ilimitada, até porque no Brasil esse tipo de financiamento só é disponível em alguns poucos bancos oficiais. Mas essa afirmação também não significa que tais recursos estejam fora do alcance da maioria das PMEs.

Tome-se como exemplo o BNDES. Em 2003, excluídos os financiamentos destinados à agropecuária, o banco realizou cerca de 33 mil operações de financiamento para as micro, pequenas e médias empresas, que movimentaram um volume de recursos da ordem de $\mathrm{R} \$$ 5,7 bilhões. Isso representa uma média de $\mathrm{R} \$ 175 \mathrm{mil}$ por operação. Do total de recursos emprestados, cerca de $82 \%$ envolveram financiamentos pelo FINAME e pelo BNDES Automático, que, como se sabe, consideram prazos e custos compatíveis com as necessidades de capitalização das PMEs brasileiras. Ainda, é relevante destacar que mais de $55 \%$ dos recursos do BNDES foram repassados às PMEs por meio dos 86 bancos privados que operam como agentes daquele banco estatal (BNDES, 2004a).

O Banco do Brasil, a Caixa Econômica Federal e o Banco do Nordeste, por outro lado, disponibilizam para as

Esse dado mostra que os proprietários-gestores da maioria das PMEs pesquisadas não estão financiando de maneira adequada a aquisição de bens de capital, pois têm se utilizado de fundos de curto prazo para essa finalidade. E pior: também 11 das 15 empresas pesquisadas utilizavam-se da inadimplência junto a fornecedores e governo como forma de gerar recursos de curto prazo para financiar as suas operações, incluindo-se aí o financiamento dos investimentos em bens de capital. Isso ocorre por indisponibilidade de créditos de longo prazo ou por incapacidade dos proprietários-gestores em obtê-los? Baty (1994) menciona que a crença popular indica que o insucesso da maioria das PMEs pode ser atribuído ao financiamento inadequado. No entanto, segundo o autor, a realidade mostra que a maioria dos insucessos pode ser atribuída "ao gerenciamento inepto, onde o financiamento inadequado é somente um dos sintomas".

Ainda assim, esse comportamento dos sócios-gestores das PMEs ao financiar os seus bens de capital com recursos de curto prazo poderia ser justificado como decorrência da falta de acesso a créditos de longo prazo e com custos razoáveis, como ressaltam insistentemente muitas das entidades representativas daquelas empresas
PMEs financiamentos do PROGER - Programa de Geração de Emprego e Renda - com taxas da ordem da TJLP $+5,3 \%$ aa com 12 meses de carência e 48 meses de amortização (SEBRAE, 2002). Essa linha de crédito procura criar condições tão facilitadas de acesso que, além das PMEs, recém-formados e proprietários de negócios que operam na informalidade podem obtê-la junto àqueles agentes financeiros (CEF, 2004).

Se créditos, ainda que limitados, existem, como justificar a aparente incapacidade das PMEs na utilização dos fundos de longo prazo? Para poder melhor entender esse problema é necessário identificar as condições exigidas pelos bancos para a concessão desse tipo de financiamento. Segundo o BNDES, para se qualificarem às suas linhas de crédito as empresas necessitam satisfazer alguns pré-requisitos: estar em dia com obrigações fiscais, tributárias e sociais, apresentar cadastro satisfatório, ter capacidade de pagamento demonstrada por um plano de negócios consistente e dispor de garantias suficientes para cobertura do risco da operação (BNDES, 2004b). Da mesma forma, os demais bancos oficiais estabelecem os seus próprios requisitos para a concessão de créditos de longo prazo que, no geral, são muito semelhantes aos estabelecidos pelo BNDES. 
Na pesquisa realizada como parte deste trabalho verificou-se que 10 das 15 empresas pesquisadas possuíam impostos e / ou contribuições sociais em atraso que as impediam de atender a esse pré-requisito dos bancos. O segundo requisito - apresentar um cadastro satisfatório - implica, em primeiro lugar, não possuir restrições de crédito junto à SERASA, ao CADIN ou outros órgãos de proteção ao crédito. Na pesquisa realizada identificou-se que 5 das 15 empresas pesquisadas tinham restrições apontadas pela SERASA e / ou CADIN. Porém, ter um cadastro satisfatório não se limita a "ter um nome limpo". Um bom cadastro, no entender dos bancos é aquele que apresenta um balanço patrimonial e um demonstrativo de resultados que possa mostrar à instituição financeira a solidez patrimonial da empresa que está solicitando o financiamento. Como já se mencionou, 13 das 15 PMEs pesquisadas não possuíam demonstrativos contábeis que pudessem traduzir fielmente a sua situação patrimonial e de geração de lucros. E, mesmo se o tivessem, 10 delas estariam mostrando prejuízo, o que poderia representar forte restrição à concessão do crédito pretendido.

Demonstrar capacidade de pagamento implica em demonstrar a capacidade de gerar lucro. Em virtude do já exposto, dispensam-se maiores comentários sobre este aspecto. No entanto, deve-se considerar também que a capacidade de pagamento passa necessariamente por convencer a instituição financeira de que a aplicação dos recursos pretendidos irá gerar caixa suficiente para cobrir os juros e a amortização dos fundos emprestados. Isso se pode fazer por meio de um plano de negócios formal que defina com clareza onde a empresa pretende chegar no médio / longo prazo e, principalmente, como ela irá consegui-lo. Na pesquisa realizada com as PMEs verificou-se que somente 2 das 15 empresas pesquisadas possuíam um plano de negócios formalmente estruturado. Em muitas das demais firmas, os proprietáriosgestores sequer conseguiram verbalizar onde suas empresas deveriam chegar ao final de 5 anos.

Finalmente, com relação às garantias reais, somente 3 das 15 empresas pesquisadas indicaram possuir bens que pudessem lastrear eventuais operações de crédito de longo prazo. Nenhum do entrevistados declarou conhecer o fundo de aval disponível para as operações do BNDES denominado FGPC - Fundo de Garantia para a Promoção da Competitividade, que dispensa de garantias reais as empresas com faturamento bruto anual menor que $\mathrm{R} \$ 10,5$ milhões em projetos de financiamento menores que R\$ 500 mil.

Como resultado de toda essa impossibilidade de atender aos pré-requisitos das instituições financeiras, a pesquisa revelou que somente 2 das 15 empresas analisadas tinham obtido alguma forma de financiamento de longo prazo para a aquisição de bens de capital nos últimos 5 anos. Também ficou evidente uma provável correlação entre a não obtenção das linhas de crédito de longo prazo com a atualidade tecnológica das empresas pesquisadas: das 15 PMEs consideradas na pesquisa, somente 3 avaliaram sua tecnologia presente como atual e satisfatória.

\section{A práticas gerenciais inadequadas PMEs seriam a principal causa da sua incapacidade em obter recursos para investimentos.}

Como se observa, os dados e informações aqui mostrados permitem estabelecer mais uma hipótese: a impossibilidade de obtenção de fundos de longo prazo para a aquisição de bens de capital pelas PMEs estaria muito mais relacionada a limitações existentes dentro da própria empresa, conseqüência da incapacidade gestora de seus proprietários, do que da indisponibilidade de linhas de crédito para atender a esse segmento empresarial.

É interessante destacar, complementando, que em pesquisa realizada junto a 411 micro e pequenas empresas (MPEs), o SEBRAE-SP identificou que dentre aquelas que solicitaram mas não conseguiram empréstimos bancários, $40 \%$ não os obtiveram por falta de garantias reais, $23 \%$ por problemas de apontamento junto a SERASA / CADIN ou por inadimplência da empresa junto aos bancos, $12 \%$ por falta de documentos suficientes, $18 \%$ por diversas outras razões e somente $7 \%$ em virtude de linhas de crédito fechadas nos bancos (SEBRAE, 2004a). Esses dados, de certa forma, confirmam em um universo mais amplo as considerações feitas por este trabalho. Ainda assim, a conclusão estabelecida pelo SEBRAE ao analisar os dados de sua pesquisa afirma que "a exigência de garantias reais e o excesso de documentos exigidos são fortes barreiras à concessão de empréstimos bancários às MPEs" (SEBRAE, 2004a). Será que o problema é realmente esse? E a qualificação dos proprietários-gestores das MPEs para administrar adequadamente suas empresas, não deveria ser destacada? Muito pouca relevância tem sido dada a esse aspecto na grande maioria das discussões que cercam esse assunto (GONÇALVES, 2000). 


\section{CONCLUSÕES}

Muito se tem discutido sobre o acesso ao crédito por parte das PMEs. Em geral, a linha de argumentação seguida por aqueles que se envolvem nesse debate invariavelmente gira em torno do volume de crédito colocado à disposição das PMEs pelos agentes financeiros ou foca a necessidade de redução das "exigências burocráticas" para a concessão de empréstimos àquelas empresas. Pouco se discute sobre a geração de lucro pelas PMEs como ferramenta viabilizadora de recursos para reforçar o seu capital de giro e também para permitir a realização dos necessários investimentos em bens de capital. Quase nunca se questiona a real capacitação dos proprietáriosgestores dessas empresas.

Para contribuir com essa discussão, este artigo procurou levantar algumas hipóteses a partir do comportamento dos proprietários-gestores das PMEs pesquisadas. As práticas gerenciais inadequadas desenvolvidas pelos sócios-gestores daquelas empresas seriam a principal causa da sua incapacidade de obter os recursos necessários para os investimentos em bens de capital. Ações incompatíveis com as boas práticas de gestão reduzem, de maneira significativa, a capacidade de geração de lucro das PMEs. Isso inviabilizaria a consideração dos capitais próprios como fontes de recursos de longo prazo para essas empresas, sejam eles na forma de lucros retidos ou na de aportes de capital. De maneira análoga, o despreparo dos sóciosgestores na condução dos aspectos gerenciais de seus respectivos negócios os impediria de atender aos prérequisitos das instituições financeiras, o que tornaria praticamente impossível o acesso das PMEs às linhas de crédito de longo prazo disponíveis no mercado.

Se essas hipóteses se confirmarem, há que se recomendar uma profunda alteração nos padrões de discussão sobre o financiamento das PMEs. Ao invés de se centrar os debates em torno do acesso ao crédito, as idéias deveriam gravitar em torno de como melhorar a qualificação gerencial dos proprietários-gestores daquele tipo de empresa. Isso poderia ser feito por meio de ações a serem realizadas pelos órgãos representativos das PMEs (SEBRAE, SIMPI, SIMPEC dentre outros) e outras par- tes interessadas, com o objetivo de: (1) conscientizar os sócios-gestores das PMEs sobre os problemas de gestão existentes e seu impacto sobre o desempenho daquelas empresas; (2) incentivá-los a aumentar o seu grau de educação formal, principalmente aprendendo os conceitos básicos da Contabilidade; (3) expô-los a treinamentos periódicos em tecnologia de gestão empresarial, e sobretudo, (4) criar condições para que os proprietáriosgestores das PMEs estejam abertos para novas idéias e para novas formas de gestão para as suas empresas.

Há, ainda, que se considerar também o importante papel que poderia vir a ser exercido pelos contadores para a melhoria da qualidade de gestão das PMEs. De fato, esses profissionais em geral atuam como conselheiros dos proprietários-gestores para assuntos de gestão empresarial e poderiam tornar-se importantes aliados na melhoria da sua qualificação gerencial.

Em paralelo, atenção também deveria ser dispensada aos futuros empresários e gestores das PMEs para melhor capacitá-los a gerir suas futuras empresas. Deve-se ressaltar que, embora as PMEs representem a esmagadora maioria das empresas existentes e serem responsáveis por mais de $60 \%$ dos empregos gerados (PUGA, 2000), as faculdades de Administração de Empresas concentram o cerne de seus conteúdos curriculares nas grandes organizações e no glamour do "Corporate America". Por isso, aqueles que se interessam pelo fomento das atividades relacionadas às PMEs deveriam também atuar junto às instituições de ensino para incluir as discussões relativas ao empreendedorismo e à gestão das PMEs no debate acadêmico das instituições que se dedicam ao ensino de Administração de Empresas.

Finalizando, destaque-se que, ainda que as hipóteses aqui sugeridas não se provem inteiramente verdadeiras - o que é muito improvável - as recomendações feitas continuarão válidas. A sua implementação só poderá contribuir para um melhoramento do nível de profissionalismo dos gestores das PMEs, com reflexos positivos sobre a sua competitividade e a sua performance financeira, características tão necessárias hoje às pequenas e médias empresas brasileiras no contexto de uma economia aberta e globalizada.

\section{Artigo recebido em 12/08/2004 \\ Aprovado para publicação em 24/11/2005}

\begin{tabular}{|c|c|c|c|}
\hline $\begin{array}{l}{ }^{1} \text { Outras formas de capitalização exis- } \\
\text { tem (emissões de ações, por exem- } \\
\text { plo), mas, no geral, estão fora do al- } \\
\text { cance das PMEs brasileiras e, por essa } \\
\text { razão, não serão aqui consideradas. }\end{array}$ & $\begin{array}{l}{ }^{2} \text { De forma simplificada, a soma do } \\
\text { ativo circulante }(\mathrm{AC})+\text { ativo perma- } \\
\text { nente }(\mathrm{AP}) \text { deve ser igual à soma do } \\
\text { passivo circulante }(\mathrm{PC})+\text { patrimônio } \\
\text { líquido }(\mathrm{PL}) \text {, ou seja } \mathrm{AC}+\mathrm{AP}=\mathrm{PC}+\end{array}$ & $\begin{array}{l}\text { PL. Pode-se reescrever essa relação } \\
\text { como } \mathrm{AC}-\mathrm{PC}=\mathrm{PL}-\mathrm{AP} \text {. Ora, se o } \\
\text { capital circulante líquido é negativo, } \\
\mathrm{AC}-\mathrm{PC}<0 \text {, então necessariamente } \\
\mathrm{PL}-\mathrm{AP}<0 \text { ou seja, } \mathrm{AP}>\mathrm{PL} \text {. E }\end{array}$ & $\begin{array}{l}\text { isso só será possível se recursos do } \\
\text { passivo circulante (PC), de curto pra- } \\
\text { zo, tiverem sido usados para adqui- } \\
\text { rir itens do ativo permanente (bens } \\
\text { de capital). }\end{array}$ \\
\hline
\end{tabular}




\section{- Referências Bibliográficas}

ALMEIDA, Martinho I. R. Desenvolvimento de um modelo de planejamento estratégico para grupos de pequenas empresas. São Paulo, 1994. 175 p. Tese (Doutorado) - Faculdade de Economia, Administração e Contabilidade, Universidade de São Paulo.

BATY, Gordon B. Pequenas e médias empresas dos anos 90 - guia do consultor e do empreendedor. São Paulo: Makron, 1994

BNDES. Boletim MPME - micro, pequenas e média empresas. [On line]. Rio de Janeiro, Junho 2004. Texto disponível na Internet: <http:// www.bndes.gov.br/empresa/ download/mpme.pdf > $12 \mathrm{Jul}$, 2004a].

BNDES. Dúvidas e perguntas mais freqüentes. [On line]. Rio de Janeiro, Junho 2004. Texto disponível na Internet: <http:// www.bndes.gov.br/produtos/faq/ bloco1.asp > [19 Jul, 2004b].

BNDES. Porte de empresa. [On line]. Rio de Janeiro, Junho 2004. Texto disponível na Internet: <http:// www.bndes.gov.br/produtos/ download/02cc64.pdf. > [20 Jul, 2004c].

BRASIL. Lei 9.841 de 05 de outubro de 1999. Diário Oficial da República Federativa do Brasil, Brasília, 06 de outubro de 1999.
BRASIL. Decreto 5.028 de 31 de março de 2004. Diário Oficial da República Federativa do Brasil, Brasília, 01 de abril de 2004 .

BRYMAN, Alan. Research methods and organizations studies. London, Routledge, 1995.

CEF - CAIXA ECONÔMICA FEDERAL. PROGER - programa de geração de emprego e renda. [On line]. Brasília, Maio 2004. Texto disponível na Internet: <http://www.caixa.gov.br/ voce/Produtos/Linhas_de_Credito/ PROGER > [27 Jul, 2004]

GONÇALVES, Antônio; KOPROWSKI, Sido Otto. Pequena Empresa no Brasil. São Paulo: Edusp, 1995.

(Org.) Pequena empresa - o esforço de construir. São Paulo: Imprensa Oficial do Estado, 2000.

LONGENECKER, Justin G.; MOORE, Carlos W.; PETTY, J. Willian. Administração de pequenas empresas - ênfase na gerência empresarial. São Paulo: Makron Books, 1998.

MARCONI, Maria de A.; LAKATOS, Eva M Fundamentos de metodologia científica. 5. ed. São Paulo: Atlas, 2003.

MOREIRA, Maurício M.; PUGA, Fernando P. Como a indústria financia o seu crescimento: uma análise do Brasil pós-plano real. Rio de Janeiro, BNDES - Textos para Discussão No. 84 - outubro, 2000.
OLIVEIRA, Alex-Sandro M. de. Informações contábil-financeiras para empreendedores de empresas de pequeno porte. São Paulo, 2001. 154 p. Dissertação (Mestrado) - Faculdade de Economia, Administração e Contabilidade, Universidade de São Paulo.

PATTON, Michael Q. Qualitative evaluation and research methods. Newbury Park, CA: Sage, 1990.

PICKLE, Hal B.; ABRAHAMSON, Royce L. Small business management. $5^{\text {th }}$ ed. New York: John Wiley, 1990.

PINHEIRO, Maurício. Gestão e desempenho das empresas de pequeno porte. São Paulo, 1994. 269 p. Tese (Doutorado) - Faculdade de Economia, Administração e Contabilidade, Universidade de São Paulo.

PORTER, Michael E. Estratégia competitiva. Rio de Janeiro: Campus, 1986.

PUGA, Fernando Pimentel. Experiências de apoio às micro, pequenas e médias empresas nos Estados Unidos, na Itália e em Taiwan. Rio de Janeiro: BNDES - Textos para Discussão No. 75 - fevereiro, 2000.

SEBRAE. Como obter financiamento série negócio próprio. São Luiz: SEBRAE-MA, 2002.

SEBRAE. $O$ financiamento das MPEs no estado de São Paulo - sondagem de opinião. São Paulo: SEBRAE-SP, abril 2004a.
SEBRAE. Legislação básica da micro e pequena empresa. [On line]. Brasília, Março 2004. Texto disponível na Internet: <http:// w w w. s e b r a e . com. b r/b r / aprendasebrae/estudosepesquisas. asp > [20 Jul, 2004b].

SELLTIZ, C. et al. Métodos de pesquisa nas relações sociais. São Paulo: E.P.U. Editora Pedagógica e Universitária, 1974.

SILVA, Daniel Salgueiro; et al.. Manual de procedimentos contábeis para micro e pequenas empresas. 5. ed. Brasília: CFC / SEBRAE, 2002.

SINGH, A. Corporate financial structures in developing countries. Washington D.C., 1992 (IFC Technical Paper, 1) apud MOREIRA, Maurício M. PUGA, Fernando P. Como a indústria financia o seu crescimento: uma análise do Brasil pós-plano real. Rio de Janeiro: BNDES - Textos para Discussão No. 84 - outubro, 2000

YIN, Robert. Case study research: de sign and methods. $6^{\text {th }}$ ed. Newbury Park, CA: Sage, 1990.

ZONENSCHAIN, C. N. Estrutura de capital das empresas no Brasil. Revista do BNDES. Rio de Janeiro, v. 5 n. 10 , p. 63-92, dez. 1998.

\section{- Sobre os autores}

\section{Wagner Cezar Lucato}

Doutorando do Depto. de Eng. de Produção da FEAU - UNIMEP

Endereço: R. Padre Manoel de Paiva, 264 - Ap. 42 - CEP 09070-230 - Santo André - SP

Telefone: (11) 4438-1803

E-mail: wlucato@terra.com.br

\section{Milton Vieira Júnior}

Prof. Doutor do Depto. de Eng. de Produção da FEAU - UNIMEP

Endereço: Rod. Santa Bárbara-Iracemápolis, Km 01 - CEP 13450-000 - Santa Bárbara D’Oeste - SP

Telefone: (19) 3124-1767

E-mail: mvieira@unimep.br 